\title{
Does intensive upper limb treatment modality Hybrid Constrained Induced Movement Therapy (H-CIMT) improve grip and pinch strength or fatigability of the affected hand?
}

Citation for published version (APA):

Brauers, L., Geijen, M. M. E., Speth, L. A. W. M., \& Rameckers, E. A. A. (2017). Does intensive upper limb treatment modality Hybrid Constrained Induced Movement Therapy (H-CIMT) improve grip and pinch strength or fatigability of the affected hand? Journal of Pediatric Rehabilitation Medicine, 10(1), 11-17. https://doi.org/10.3233/PRM-170406

Document status and date:

Published: 17/03/2017

DOI:

10.3233/PRM-170406

Document Version:

Publisher's PDF, also known as Version of record

Document license:

Taverne

Please check the document version of this publication:

- A submitted manuscript is the version of the article upon submission and before peer-review. There can be important differences between the submitted version and the official published version of record. People interested in the research are advised to contact the author for the final version of the publication, or visit the DOI to the publisher's website.

- The final author version and the galley proof are versions of the publication after peer review.

- The final published version features the final layout of the paper including the volume, issue and page numbers.

Link to publication

\footnotetext{
General rights rights.

- You may freely distribute the URL identifying the publication in the public portal. please follow below link for the End User Agreement:

www.umlib.nl/taverne-license

Take down policy

If you believe that this document breaches copyright please contact us at:

repository@maastrichtuniversity.nl

providing details and we will investigate your claim.
}

Copyright and moral rights for the publications made accessible in the public portal are retained by the authors and/or other copyright owners and it is a condition of accessing publications that users recognise and abide by the legal requirements associated with these

- Users may download and print one copy of any publication from the public portal for the purpose of private study or research.

- You may not further distribute the material or use it for any profit-making activity or commercial gain

If the publication is distributed under the terms of Article 25fa of the Dutch Copyright Act, indicated by the "Taverne" license above,

Download date: 26 Apr. 2023 
IOS Press

\title{
Does intensive upper limb treatment modality Hybrid Constrained Induced Movement Therapy (H-CIMT) improve grip and pinch strength or fatigability of the affected hand?
}

\author{
L. Brauers ${ }^{\mathrm{a}, *}$, M.M.E. Geijen ${ }^{\mathrm{a}, \mathrm{b}}$, L.A.W.M. Speth ${ }^{\mathrm{a}}$ and E.A.A. Rameckers ${ }^{\mathrm{a}, \mathrm{b}, \mathrm{c}}$ \\ ${ }^{\mathrm{a}}$ Adelante Centre of Expertise in Rehabilitation and Audiology, Valkenburg and Hoensbroek, The Netherlands \\ ${ }^{\mathrm{b}}$ Department Functioning and Rehabilitation, CAPHRI, FHML, UM Maastricht, The Netherlands \\ ${ }^{\mathrm{c}}$ Master of Specialised Physical Therapy, AVANSplus, Breda, The Netherlands
}

Accepted 19 November 2016

\begin{abstract}
.
PURPOSE: To investigate the effects of Hybrid-Constrained Induced Movement Therapy (H-CIMT), defined as CIMT combined with Bimanual Intensive Movement Therapy (BIMT), on grip and pinch strength and fatigability we measured grip and pinch strength and fatigability during clinical H-CIMT.

METHODS: The children participated in a H-CIMT model organized in a therapeutic summer-camp. Children received 90 hours of intensive treatment. Grip and pinch strength and fatigability was measured and fatigue was calculated according to a Static Fatigue Index (SFI).

RESULTS: Pinch strength significantly increased, grip strength did not increase significantly. A non-significant decrease was seen in SFI in pinch and grip.

CONCLUSIONS: H-CIMT showed to be effective in increasing muscle pinch strength in the AH. Effectiveness in decreasing muscle fatigue during grip and pinch tests is not yet shown although there was a tendency towards a decrease in muscle fatigue. However, the long-term effects on these aspects are also important in future research.
\end{abstract}

Keywords: H-CIMT, BIMT, strength, static fatigue index, cerebral palsy

\section{Introduction}

Children with unilateral Cerebral Palsy (CP) usually present with more motor impairments in the upper limb then lower limb, such as muscle weakness (maximal grip strength and endurance) and spasticity [1]. Both impairments are important factors causing limitations on daily activities [1]. To train daily activities a large

\footnotetext{
*Corresponding author: Lieke Brauers, Adelante Center of Expertise in Rehabilitation and Audiology, Zandbergsweg 111, 6432 CC Hoensbroek, The Netherlands. Tel.: +31 4552823 58; E-mail: 1.brauers@adelante-zorggroep.nl.
}

variety of treatment options are possible [2,3]. In these treatment options H-CIMT and BIMT have proven to be very effective in improving hand function in children with unilateral $\mathrm{CP}$ [2-5]. The intensity of the treatment modalities seems to be a key element in improving hand functions and strength $[4,6]$. Both treatment modalities are based on a well-designed context for motor learning related to the needs and daily activities of these children in a time period of 2-8 weeks for $60-90$ hours $[2,4]$. They also have shown to be equally effective at the level of activity of the International Classification of Functioning, Disability and Health for Children and Youth (ICF-CY) [2,4]. 
In both modalities, no indication of maximal grip and pinch strength improvements have been reported although it is known that in children with unilateral CP maximal grip strength is decreased up to $30-50 \%$ in the affected side, hampering the performance of daily activities [7-9]. Furthermore, grip strength regulation in the affected hand $(\mathrm{AH})$ has shown to be impaired in children with unilateral CP [8]. However, the effects of treatment on maximal pinch strength and pinch strength regulation are unknown.

Next to maximal muscle strength muscle fatigability seems to be an important factor in daily activities. In most of these activities, such as using a fork and knife, lifting and carrying a crate, bag or box, the AH is used as assisting hand in a longer time period, indicating the need of a well-trained level of muscle strength and low muscle fatigability. However, in children with $\mathrm{CP}$ no studies are performed related to upper limb fatigability. In adolescents with $\mathrm{CP}$, two studies have investigated muscle fatigability in the upper limb with conflicting results [10,11]. Meeteren et al. [10] showed that young adults with unilateral CP had higher muscle fatigability in grip strength in both hands compared to healthy young adults based on a "Static Fatigue index" (SFI). In contrast, Doix et al. [11] showed that there was no difference in endurance time and EMG median frequency slope between adolescents with unilateral CP and typical developing adolescents during isometric elbow flexion on a low force level. The contradictory results in these studies may have been due to small sample sizes. However, it is also clear that the two studies investigate different muscle groups. In persons with $\mathrm{CP}$, distal muscle groups are in general more affected than proximal muscle groups. This is in agreement with the outcomes of both studies in which adolescents in the study of Meeteren et al. [10] show more fatigability compared to the adolescents in the study of Doix et al. [11]. However, fatigability in children with $\mathrm{CP}$ in both distal as well as proximal muscle groups remains unknown.

Studies related to upper limb fatigability are until now mainly focused around patients with Multiple Scerosis (MS). However, these studies may be very relevant in investigating muscle fatigability in children with $\mathrm{CP}$ since both patients groups show difficulties in their distal muscles $[1,12]$. Also, studies in fatigability in patients with MS are also concentrated to upper limb. In these studies, muscle fatigability in the upper limb is measured by means of a "Static Fatigue Index" (SFI), which is a very relevant tool for quantitatively measuring muscle fatigability in these patients.
Current research will use a modified version of the SFI based on the specific muscle force regulation pattern in children with CP $[9,12]$. It is hypothesized that maximal grip strength will not improve, pinch strength will improve by using intensively pinch grip in fine motor tasks and grip and pinch fatigability will reduce practicing daily tasks intensively.

\section{Methods}

\subsection{Participants}

All children $(\mathrm{N}=23)$ included in the clinical $\mathrm{H}$ CIMT are children with unilateral $\mathrm{CP}$ that have been in a H-CIMT training modality. Children were included if they were between 12 and 18 years old and Dutch speaking. Based on functional levels children were included if they had level I, II or III of the Manual Ability Classification System (MACS) [13] and level I or II of the Gross Motor Function Classification System (GMFCS) [14]. Informed consents were contained for all children.

\subsection{Interventions}

The children participated in a H-CIMT model organised in a therapeutic summer-camp called "Hand in hand Survival Kamp" in the period from 2007 till 2012 in Adelante Rehabilitation Centre in Valkenburg, the Netherlands. Children received 90 hours of intensive treatment during a two-week period in blocks of one-hour sessions. Each day consisted of six hours of CIMT and two hours of BIMT. All activities were based on the needs of each child or based on the typical summer camp activities (survival, sports, crafts, preparing the food). These task-specific, context-specific and goal-oriented activities were practised very intensively.

During CIMT both part practice, shaping as well as needs-based activities and daily life based activities were performed using a thick oven-glove with splint at the non-affected hand (NAH).

The children stayed over during the week and stayed at home during the weekend. Progress made during therapy was demonstrated to the parents to continue practicing at home during the weekend and to embed in the home situation.

During the two hours of BIMT, bimanual sport activities (sailing, archery), recreational activities (painting, making crafts, making music) and survival activ- 


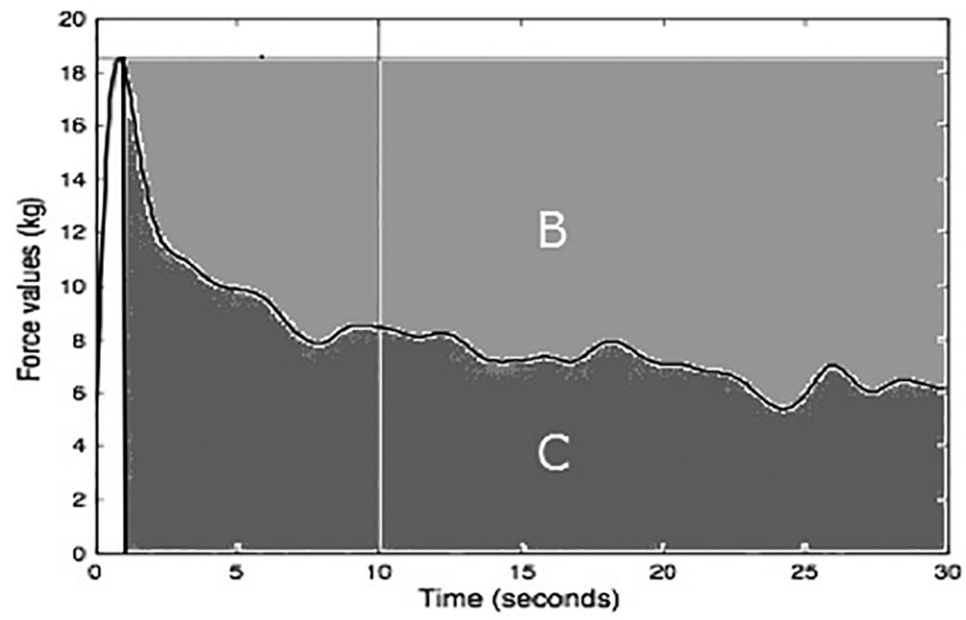

Fig. 1. Strength-time curve to calculate SFI.

Table 1

Subject characteristics

\begin{tabular}{llc}
\hline & & Total \\
\hline Number of children & & 23 \\
Mean age \pm SD & & 14 y $8 \mathrm{~m} \pm 1$ y $11 \mathrm{~m}$ \\
Gender & Boys & 12 \\
& Girls & 11 \\
Hemiparesis & Left & 13 \\
& Right & 10 \\
MACS & I & 3 \\
& II & 7 \\
GMFCS & III & 13 \\
& I & 13 \\
& II & 10 \\
\hline
\end{tabular}

ities (tree climbing, crossing rope bridges over water, slack line walking) were performed.

Professional therapists supervised students (occupational and physical therapy (OT and PT)), who guided the children during the day. All activities were individualized based on the needs of the child and both individual and group based activities were performed. All students and supervisors were trained by certified professionals for 8 hours one day before camp in preparation of the camp to be able to practice in a task-oriented approach. The professionals who trained all students and supervisors were the same over all years.

\subsection{Measurements}

There were three measurement moments, 8 weeks prior to camp, at the first day of the camp (double baseline T0-T1), and at the last day of the camp (T2). A period of 8 weeks between the baseline measurements was to make sure that spontaneous changes over time were included. The participants were measured at dif- ferent times during the day, but all during a school day, which starts at 9:00 am and ends at 3:00 pm. Also, the participants were measured within a familiar environment, within school or the rehabilitation center where they often are.

Grip and pinch strength and fatigability was measured with E-Link H500 hand-kit (Biometrics; UK). A pilot study with 32 adolescents with unilateral $\mathrm{CP}$ showed a high test-retest reliability $(\mathrm{ICC}=0.99)$ for the handgrip measurement of the AH [15].

\subsubsection{Grip and pinch strength}

The participants were instructed to sit straight up in front of a laptop screen and the handgrip dynamometer and pinch meter had to be held with a 90-degree elbow bent resting on an armrest. The children performed a peak measurement with their AH first, and a sustained measurement with their AH second.

During the peak measurements the participants had to squeeze as hard as possible into the dynamometer for 5 seconds. This measurement was repeated three times. The sustained measure consisted of squeezing the handgrip and pinch meter as hard as they could for 30 seconds. It was important that the peak value was reached within the first 10 seconds. This was also clearly stated to the participants. During the measurement the participants were constantly encouraged to keep on squeezing.

\subsection{Data analysis}

\subsubsection{Static muscle fatigability}

To calculate the SFI, children perform strength measurements as described above using the E-link handgrip strength meter and pinch meter. This results in 
Table 2

Outcome variables of the SFI and peak strength measurements of the AH

\begin{tabular}{|c|c|c|c|c|c|c|c|c|c|}
\hline & \multicolumn{3}{|c|}{ T0 } & \multicolumn{3}{|c|}{$\mathrm{T} 1$} & \multicolumn{3}{|c|}{$\mathrm{T} 2$} \\
\hline & Mean (SD) & Median & Min-Max & Mean (SD) & Median & Min-Max & Mean (SD) & Median & Min-Max \\
\hline Peak pinch $\mathrm{AH}$ & $2.88(1.40)$ & 2.60 & $0.90-6.20$ & $2.46(1.52)$ & 2.60 & $0.00-6.70$ & $3.21(2.15)^{*}$ & 2.40 & $0.90-10.80$ \\
\hline Peak grip AH & $8.14(4.49)$ & 7.20 & $0.90-18.80$ & $7.20(4.73)$ & 7.10 & $0.00-19.40$ & $8.94(5.07)$ & 9.40 & $1.00-20.90$ \\
\hline SFI pinch $\mathrm{AH}$ & $59.13(23.57)$ & 61.43 & $-18.06-85.40$ & $60.50(17.21)$ & 57.32 & $33.83-91.90$ & $49.81(20.28)$ & 55.97 & $6.60-86.42$ \\
\hline SFI grip AH & 55.63 (17.09) & 56.17 & $21.32-90.56$ & $54.77(15.22)$ & 52.56 & $32.96-88.42$ & $57.03(13.83)$ & 57.13 & $22.89-79.28$ \\
\hline
\end{tabular}

$\mathrm{SFI}=$ static fatigue index, $\mathrm{AH}=$ affected hand, ${ }^{*}=$ significant $(p<0.05)$.
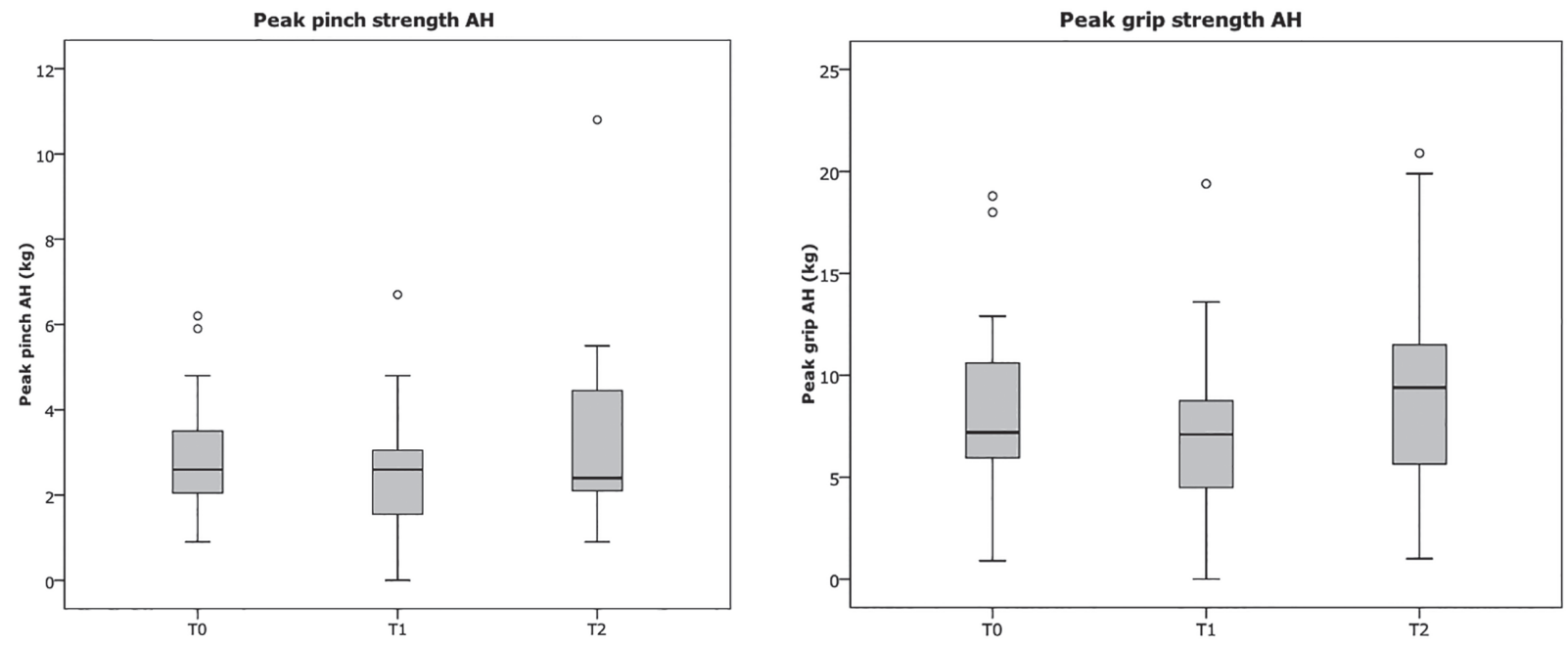

Fig. 2. Median and upper and lower quartiles of the pinch and grip strength measurement of the AH at T0, T1 and T2. The circles represent outliers and the whiskers represent the minimum and maximum values.

30 seconds strength-time curves on which the SFI can be applied. A high SFI indicates that there is more fatigability, whereas a low SFI less fatigability indicates.

The SFI is calculated by defining the peak force within the first 10 seconds and calculating a ratio between the area under the force-time curve (AUC) and the hypothetical area under the curve (HAUC) had there not have been a decline in force from this peak force [12]. In Fig. 1, a schematic overview of the strength-time curve is shown, with the different areas necessary to calculate SFI. In this figure, $\mathrm{C}$ stands for the AUC, and B for the HAUC. The AUC and HAUC are calculated from the point where peak force has been reached. This peak force is identified within the first 10 seconds of the curve. SFI will be calculated as follows: $\mathrm{SFI}=100 \% \times\left(1-\frac{\mathrm{C}}{\mathrm{B}+\mathrm{C}}\right)$. The SFI calculations will be performed using Matlab.

A pilot study in age matched children with $\mathrm{CP}(\mathrm{N}=$ 30) determined that the SFI has a fair to good test retest reliability in the pinch meter $(\mathrm{ICC}=0.74)$, with a SEM of $10.38 \%$ and a SDD of $28.77 \%$. The handgrip dynamometer showed a moderate test retest reli- ability (ICC $=0.62)$ with a SEM of $9.11 \%$ and SDD $25.25 \%$ [16].

\subsubsection{Statistics}

Statistical analysis was performed using SPSS software (SPSS Inc., Chicago, IL). Normal distribution of data was assessed with Kolmogorov-Smirnov. Since the data was not normally distributed, a Wilcoxon signed-rank test was performed to assess if SFI, grip and pinch strength showed differences during a period of usual care (T0-T1) and after a period of H-CIMT (T1-T2). Alpha was set at 0.05. Mean values and standard deviation (SD) were calculated for both the entire group of children as well as per MACS level and percentages of maximal strength of the $\mathrm{AH}$.

\section{Results}

The subject characteristics are displayed in Table 1. Twenty-three subjects were included (12 boys and 11 girls) with a mean age of 14 years and 8 months (SD $=$ $1 \mathrm{y} 11 \mathrm{~m})$. Hemiplegia was left-sided in 13 subjects 
Table 3

Mean (SD) and median values of the SFI and peak strength measurements of the AH per MACS level

\begin{tabular}{|c|c|c|c|c|c|c|c|}
\hline & & \multicolumn{2}{|c|}{ MACS I } & \multicolumn{2}{|c|}{ MACS II } & \multicolumn{2}{|c|}{ MACS III } \\
\hline & & Mean (SD) & Median & Mean (SD) & Median & Mean (SD) & Median \\
\hline \multirow[t]{3}{*}{ Peak pinch $\mathrm{AH}$} & T0 & $3.67(1.12)$ & 2.60 & $3.60(0.54)$ & 3.50 & $2.31(0.29)$ & 2.10 \\
\hline & $\mathrm{T} 1$ & $4.23(1.23)$ & 3.10 & $2.47(0.53)$ & 2.60 & $2.04(0.34)$ & 1.90 \\
\hline & $\mathrm{T} 2$ & $5.33(2.74)$ & 5.30 & $3.67(0.57)$ & 4.30 & $2.47(0.36)$ & 2.30 \\
\hline \multirow[t]{3}{*}{ Peak grip AH } & T0 & $12.10(3.45)$ & 10.20 & $10.31(1.57)$ & 8.60 & $6.06(0.92)$ & 6.00 \\
\hline & $\mathrm{T} 1$ & $12.77(3.73)$ & 12.40 & $8.03(1.75)$ & 7.40 & $5.47(0.96)$ & 5.60 \\
\hline & $\mathrm{T} 2$ & $14.57(2.67)$ & 12.20 & $10.96(2.09)$ & 9.80 & $6.56(0.96)$ & 6.40 \\
\hline \multirow[t]{3}{*}{ SFI pinch $\mathrm{AH}$} & T0 & $57.86(13.30)$ & 54.82 & $50.42(15.91)$ & 66.25 & $63.79(3.63)$ & 62.92 \\
\hline & $\mathrm{T} 1$ & $59.56(6.45)$ & 65.33 & $57.93(5.72)$ & 55.79 & $62.01(5.92)$ & 61.35 \\
\hline & $\mathrm{T} 2$ & $45.89(12.74)$ & 42.53 & $46.05(8.77)$ & 45.55 & $52.66(5.98)$ & 57.58 \\
\hline \multirow[t]{3}{*}{ SFI grip AH } & T0 & $46.24(8.93)$ & 38.18 & $57.87(10.87)$ & 61.49 & $56.86(3.38)$ & 55.06 \\
\hline & $\mathrm{T} 1$ & $49.74(6.88)$ & 51.17 & $55.12(6.53)$ & 54.44 & $55.85(4.75)$ & 52.73 \\
\hline & $\mathrm{T} 2$ & $51.11(11.86)$ & 44.03 & $53.92(7.38)$ & 56.86 & $60.07(2.85)$ & 59.12 \\
\hline
\end{tabular}

SFI pinch AH

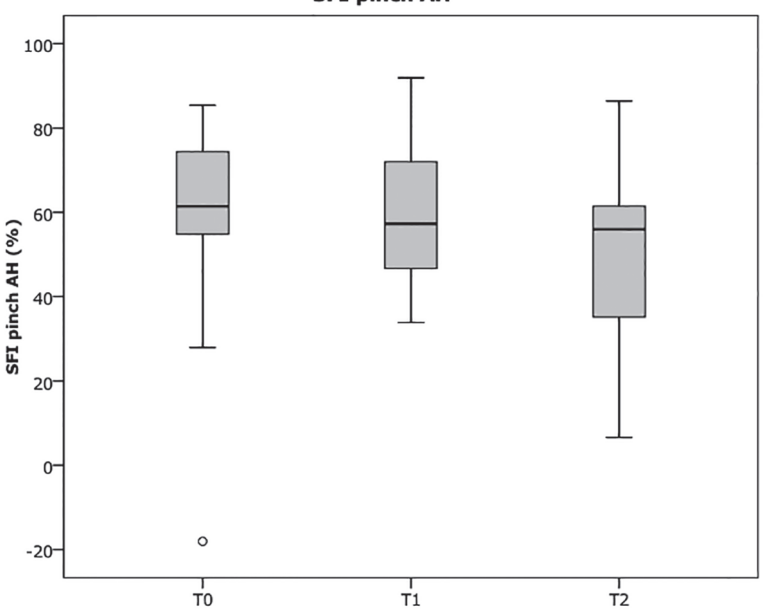

SFI grip AH

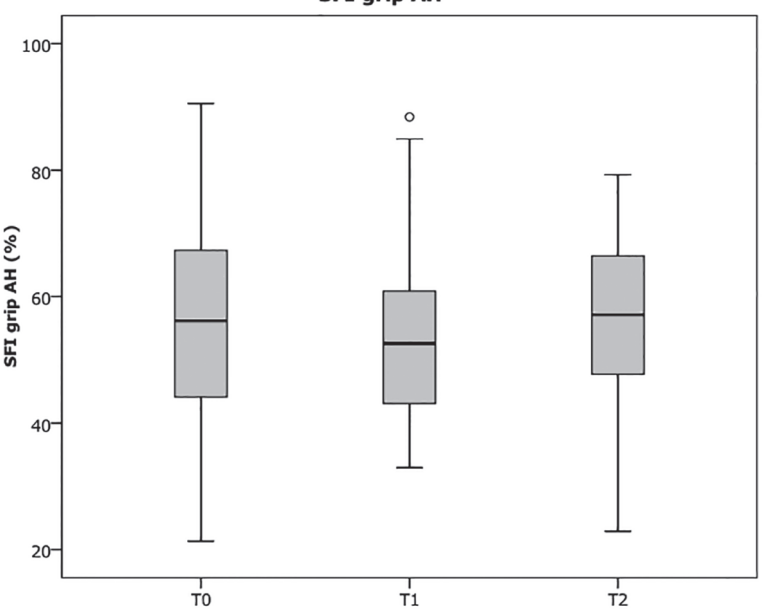

Fig. 3. Median and upper and lower quartiles of the SFI of the pinch and grip in the AH at T0, T1 and T2. The circles represent outliers and the whiskers represent the minimum and maximum values.

and right-sided in 10 subjects. According to the MACS levels, 3 subjects (13\%) were classified as level I, 7 subjects (30.4\%) as level II, and 13 subjects (56.6\%) as level III.

For the statistical analyses of the SFI only 21 subjects were used, because the data of two subjects of the measurement of $\mathrm{T} 1$ was missing. Therefore, they were excluded for the analysis. For the statistical analyses of the pinch and grip strength all 23 subjects were used.

Table 2 presents the outcome variables at T0, T1 and $\mathrm{T} 2$ by mean, standard deviation, median and minimum and maximum value. A significant difference was noted after a period of H-CIMT (T1-T2) in the strength measurement of the pinch of the AH. The pinch strength of the AH at T2 $(\mathrm{Mdn}=2.40)$ was significantly higher than the pinch strength at T1 $(\mathrm{Mdn}=$ 2.60; $\mathrm{Z}=-2.28, p=0.02$ ) (Fig. 2). No significant change was found between $\mathrm{T} 0$ and $\mathrm{T} 1$.
The SFI of the pinch measurement of the AH remained the same after a period of usual care (T0T1) and decreased after a period of H-CIMT (T1-T2) (Fig. 3). The SFI of the grip strength for the AH remained the same after a period of usual care. After a period of H-CIMT the SFI of the grip strength of the AH showed a non-significant increase (Fig. 3).

To detect differences in SFI and peak strength mean and median values were shown per MACS level and the percentage of peak strength of the AH are shown. Table 3 presents the outcome variables at T0, T1 and $\mathrm{T} 2$ by mean and standard deviation per MACS level. During the period of usual care the peak values of the pinch and grip measurement for the $\mathrm{AH}$ remained the same or decreased for MACS I, II and III. After a period of $\mathrm{H}-\mathrm{CIMT}$ pinch and grip strength of the $\mathrm{AH}$ showed a small increase. 
Table 4

Percentages pinch and grip strength and SFI of the $\mathrm{AH}$

\begin{tabular}{lrrrrr}
\hline & & \multicolumn{4}{c}{ Percentages } \\
\cline { 3 - 6 } & & $25 \%$ & $50 \%$ & $75 \%$ & $>75 \%$ \\
\hline Peak pinch AH & T0 & 2.00 & 2.60 & 3.50 & 6.14 \\
& T1 & 1.50 & 2.60 & 3.10 & 6.32 \\
& T2 & 2.00 & 2.40 & 4.60 & 9.74 \\
Peak grip AH & T0 & 5.90 & 7.20 & 11.00 & 18.64 \\
& T1 & 4.30 & 7.10 & 9.00 & 18.24 \\
& T2 & 5.20 & 9.40 & 11.60 & 20.70 \\
SFI pinch AH & T0 & 52.69 & 61.43 & 76.67 & 85.37 \\
& T1 & 44.37 & 57.31 & 73.19 & 91.27 \\
& T2 & 30.41 & 55.97 & 64.19 & 84.19 \\
SFI grip AH & T0 & 43.90 & 56.17 & 67.79 & 89.42 \\
& T1 & 42.86 & 52.56 & 61.11 & 88.07 \\
& T2 & 47.44 & 57.13 & 68.04 & 78.82 \\
\hline
\end{tabular}

The SFI of the pinch measurement of the $\mathrm{AH}$ decreased in all MACS levels after a period of H-CIMT. The SFI of the grip measurement of the AH increased in MACS I and III, and decreased in MACS II after a period of H-CIMT.

To see if there were differences in strength shown Table 4 presents different percentages ranges of the pinch and grip strength and the SFI of the AH. The different percentages ranges show that there is a large difference between the smallest and the largest pinch and grip strength and SFI.

\section{Discussion}

This study investigated the effects of clinical $\mathrm{H}$ CIMT on grip- and pinch strength and grip- and pinch fatigability of the AH of children with unilateral CP. The hypothesis was that maximal pinch strength will improve, and grip strength will not improve although grip and pinch fatigability will decrease.

First, after a period of H-CIMT a significant increase was seen in pinch strength of the $\mathrm{AH}$, whereas the pinch strength remained stable during usual care period of 8 weeks. This increase was also seen in both MACS I and II, whereas in MACS III this difference was not seen. This effect is in agreement with the intensity of the fine motor activities of the affected hand during H-CIMT, using pinch strength to perform the tasks.

For the grip strength a non-significant increase was seen in the entire group, as well as for all MACS levels. No differences were found in peak values of the grip strength during the usual care period.

Second, after a period of H-CIMT a non-significant decrease was found in the SFI during the pinch test of the AH in all MACS levels. This decrease may be caused by a training effect when practicing daily tasks using this pinch grip. Fine motor object handling using pinch grip is more frequently practised in H-CIMT. In the SFI during the grip test a non-significant decrease was seen in MACS II. In MACS I and III, an increase was found during a period of H-CIMT. In general, the non-significant differences may be caused by a number of factors.

The number of participants included in the study was limited. Only 23 children completed all three measurements, which may be one of the reasons for non-significant outcomes, however the direction of the changes in pinch and grip strength and SFI are very promising, based on the fact that H-CIMT is aimed at improving functionality of the $\mathrm{AH}$ and the children are not specifically trained in strength and sustainability of force. The children may have practiced tasks in which strength and sustainability is not an issue rather than the manipulation of objects, leading to a lesser training effect in these children.

The effect of H-CIMT measured in a two-week period can be too short for change in muscle strength and fatigability, based on neuromuscular changes. Based on the fact that 13 children are classified as MACS III, showing little strength values and contradictory results compared to MACS I and II -showing higher strength levels-, the total group effects are diminished (Table 3 and 4). Probably the children with MACS III level and little strength are not capable to show large changes in strength and fatigue in this short time period, even after intensive treatment.

Furthermore, this research is based on a static fatigue index of which only a pilot study investigated the SEM and SDD [16]. By comparing the results of this study, with the pilot study, it can be concluded that for children with CP, a decrease in SFI can be seen. However, this decrease may not be large enough based on the SDD of the pinch and grip meter $(10.38 \%$ and $25.25 \%$, respectively) to be clinically relevant.

In order to generate more significant differences in grip strength and pinch and grip fatigability, more specific physiological training principles need to be embedded during H-CIMT. It seems that children with MACS III level show just small differences, questioning the effect of H-CIMT for this group, related to strength and fatigue in this two weeks period. Probably a longer period of training is needed for the children with MACS III, whereas this time period seems to be more suitable for children with MACS level I and II.

Trainability of strength and fatigue can also be questioned for adolescents with CP, after a long period of 
decreasing strength of the $\mathrm{AH}$, as showed in the study of Smits-Engelsman et al. [9].

Current research gave a first impression in the field of effect of H-CIMT on strength and fatigability in adolescents with unilateral CP. Other treatment modalities such as BIMT and HABIT-(ILE) might be more effective in enhancing muscle strength and decreasing muscle fatigability. Future research should also focus on the long-term (three to eight months) effects of the H-CIMT and BIMT therapy.

In conclusion, H-CIMT showed to be effective in increasing muscle pinch strength in the $\mathrm{AH}$ as well as in MACS I in grip strength. Effectiveness in decreasing muscle fatigue during pinch tests is not yet shown, however the results are indicating a decreasing of fatigue although not in the grip tests. Adolescents with MACS level I-II demonstrated higher pinch and grip strength and larger results compared to adolescents with MACS level III. However, the long-term effects on these aspects are also important in future research. But knowledge on the exact mechanisms to train muscle fatigability are not yet known as well as the methods for quantitatively measuring muscle fatigability.

\section{Conflict of interest}

The authors have no conflict of interest to report.

\section{References}

[1] Kim W, Park E. Causal relation between spasticity, strength, gross motor function, and functional outcome in children with cerebral palsy: a path analysis. Dev Med Child Neurol. 2011 Jan; 53(1): 68-73.

[2] Sakzewski L, Provan K, Ziviani J, Boyd R. Comparison of dosage of intensive upper limb therapy for children with unilateral cerebral palsy: how big should the therapy pill be? Res Dev Disabil. 2015 Feb; 37: 9-16.

[3] Novak I, McIntyr S, Morgan C, Campbell L, Dark L, Morton N, Stumbles E, Wilson S, Goldsmith S. A systematic review of interventions for children with cerebral palsy: state of the evidence. Dev Med Child Neurol. 2013 Oct; 55(10): 885-910.
[4] Gordon A. To constrain or not to constrain, and other stories of intensive upper extremity training for children with unilateral cerebral palsy. Dev Med Child Neurol. 2011 Sep; 4: 5661.

[5] Deppe W, Theummler K, Fleischer J, Berger C, Meyer S, Wiedemann B. Modified constraint-induced movement therapy versus intensive bimanual training for children with hemiplegia - a randomized controlled trial. Clin Rehabil. 2013 Oct; 27(10): 909-920.

[6] Eliasson A, Krumlinde-Sundholm L, Gordon A, Feys H, Klingels K, Aarts P, Rameckers E, Autti-Rämö I, Hoare B, (EUnetHTA). EnfHTA. Guidelines for future research in constraint-induced movement therapy for children with unilateral cerebral palsy: an expert consensus. Dev Med Child Neurol. 2014 Feb; 56(2): 125-137.

[7] Klingels K, Demeyere I, Jaspers E, De Cock P, Molenaers G, Boyd R, Feys H. Upper limb impairments and their impact on activity measures in children with unilateral cerebral palsy: Eur J Pediatr Neurol; 2012.

[8] Rameckers E, Janssen-Potten Y, Essers I, Smeets R. Efficacy of upper limb strengthening in children with cerebral palsy: a critical review. Research in Developmental Difficulties. 2014; (36): 87-101.

[9] Smits-Engelsman B, Rameckers E, Duysens J. Muscle force generation and force control of finger movements in children with spastic hemiplegia during isometric tasks. Developmental Medicine \& Child Neurology. 2005; (47): 337-342.

[10] Meeteren J, Van Rijn R, Selles R, Roebroeck M, Stam H. Grip strength parameters and functional activities in young adults with unilateral cerebral palsy compared with healthy subjects. J Rehabil Med. 2007; 39: 598-604.

[11] Doix A, Gulliksen A, Braendvik S, Roeleveld K. Fatigue and muscle activation during submaximal elbow flexion in children with cerebral palsy. J Electromyo Kin. 2013; 23: 721726.

[12] Severijns D, Lamers I, Kerkhofs L, Feys P. Hand grip fatigability in person with Multiple sclerosis according to hand dominance and disease progression. Journal of Rehabilitation Medicine. 2015 Feb; 47(2): 154-60.

[13] Eliasson A, Krumlinde-Sundholm L, Rösblad B, Beckung E, Arner M, Ohrvall A, Rosenbaum P. The Manual Ability Classification System (MACS) for children with cerebral palsy: scale development and evidence of validity and reliability: Dev Med Child Neurol; 2006.

[14] Palisano R, Rosenbaum P, Walter S, Russelt D, Wood E, Gahoppi B. Development and reliability of a system to classify gross motor function in children with cerebral palsy: Dev Med Child Neurol; 1997.

[15] Geijen M. Reliability and validity of the TAAC instrument during bimanual activities in children with unilateral Cerebral Palsy: Master Thesis; 2015.

[16] Brauers L. Test-retest reliability of a new fatigue index to quantitatively evaluate fatigue in children with cerebral palsy: Master Thesis; 2015. 